\title{
Abnormal Regulation of Sympathetic Nervous Activity and Heart Rate After Oral Glucose in Type 1 (Insulin-Dependent) Diabetic Patients
}

\author{
L. Hegedüs, N.J. Christensen and L. Sestoft \\ Department of Internal Medicine and Endocrinology, Herlev Hospital and Hvidøre Hospital, Klampenborg, Denmark
}

\begin{abstract}
Summary. Oral glucose administration increased plasma noradrenaline concentration significantly in seven normal subjects $(p<0.02)$, whereas in six young short-term Type 1 diabetic patients without complications plasma noradrenaline did not change. Basal plasma noradrenaline did not differ between the two groups. In the first $3 \mathrm{~h}$ after oral glucose administration, the mean heart rate in eight normal subjects was increased $3.5 \%$ above basal levels $(p<0.05)$. In contrast, no such increase was found in eight Type 1 diabetic patients after glucose administration. In two normal subjects thoroughly ex-
\end{abstract}

amined before and after oral glucose administration, we observed a significant correlation between heart rate and systolic blood pressure $(p<0.001)$ but this was not seen in two diabetic patients in whom neither heart rate nor systolic blood pressure increased. Our findings indicate that sympathetic nervous activity and cardiovascular function is abnormal in early diabetes during an oral glucose load.

Key words: Adrenaline, arterial blood pressure, heart rate, insulin, Type 1 diabetes, noradrenaline, oral glucose.
Intravenous injection of insulin increases plasma noradrenaline [1-3] as well as heart rate $[4,5]$. These effects of insulin do not require the presence of hypoglycaemia. To study the possible physiological importance of these interrelationships, we examined the rise in plasma noradrenaline (NA) and heart rate in normal subjects and in Type 1 (insulin-dependent) diabetic patients after oral glucose administration.

\section{Subjects and Methods}

Three groups of short-term diabetic patients and healthy subjects were examined after informed consent had been obtained. Pertinent clinical data are given in Table 1 . All subjects were within $10 \%$ of ideal body weight. No diabetic patient showed signs of peripheral neuropathy or retinopathy. Serum creatinine concentration and arterial blood pressure were normal in all patients and none had proteinuria. They were taking no medication except insulin. Patients and control subjects were studied after an overnight fast. The diabetic patients were not given insulin on the morning of the experiment. All subjects were investigated while they rested in the supine position.

\section{Group 1}

A Teflon cannula was inserted into an antecubital vein and kept patent with saline $(0.154 \mathrm{mmol} / \mathrm{l})$. After a 60 -min period of rest, two blood samples were drawn at 30-min intervals for determination of basal levels. Thereafter an oral glucose load $(1 \mathrm{~g} / \mathrm{kg}$ body weight) was given. The glucose was dissolved in $200 \mathrm{ml}$ of water plus $25 \mathrm{ml}$ of lemon juice. The solutions were sucked through a straw within $5 \mathrm{~min}$. The temperature of the solutions was equal to that of the room. Blood samples were obtained at $-30,0,30,60,90$ and $120 \mathrm{~min}$ relative to the glucose load. Blood loss was replaced by $0.154 \mathrm{mmol} / 1$ saline $(150 \mathrm{ml})$. The following parameters were measured: plasma glucose (glucose oxidase method), plasma C-peptide [6] and plasma noradrenaline and adrenaline [7].

\section{Group 2}

The heart rate response to oral glucose was investigated in eight diabetic patients and eight normal subjects (Table 1). After resting for $1 \mathrm{~h}$, the basal heart rate was measured for $1 \mathrm{~h}$ before an oral glucose load was given. After glucose administration the heart rate was measured continuously by a Memory Trendscope MTS 216 (Simonsen \& Weel, Albertslund, Denmark). No blood samples were obtained in these subjects during the experimental period.

\section{Group 3}

In two diabetic and two normal subjects (Table 1) heart rate and systolic and diastolic blood pressures were measured at 5-min intervals before and after an oral glucose load. The arterial blood pressure and heart rate were measured automatically by a Sentron (Bard Biochemical, Lombard, Illinois, USA).

In an additional five subjects, heart rate (three subjects) and plasma NA concentration (two subjects) were also measured in an experiment where water plus lemon juice were given without added glucose.

\section{Statistical Analysis}

Results are expressed as mean \pm SEM. Statistical significance for each variable was estimated by comparing the areas above or below baseline values after the oral glucose load using the Wilcoxon test for 
Table 1. Pertinent clinical data in three groups of diabetic patients and normal subjects

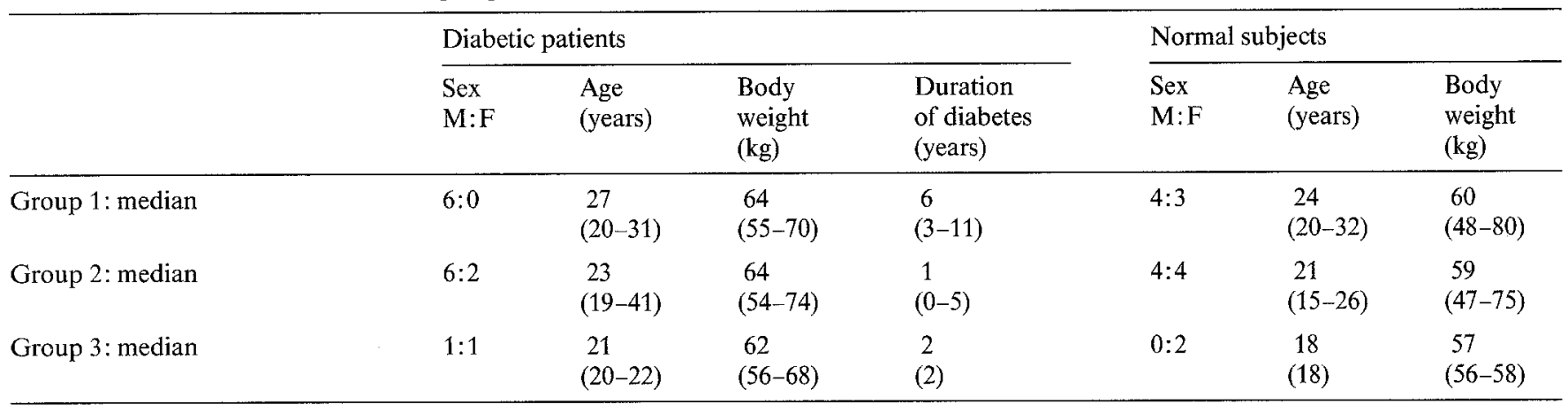

Ranges are given in parentheses

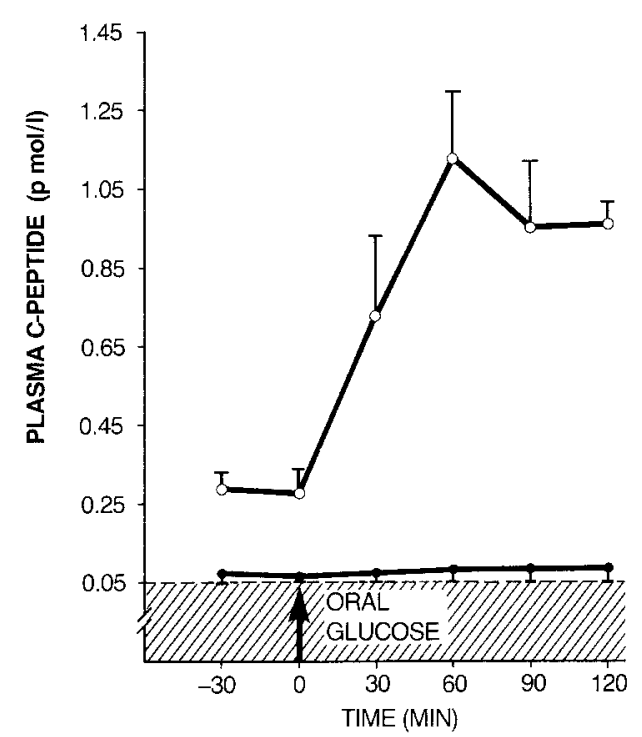

Fig. 1. Plasma C-peptide concentration (mean \pm SEM) at 30-min intervals before and after an oral glucose load in six Type 1 diabetic patients $(-)$ ) and in seven normal subjects $(\mathrm{O}-\mathrm{O})$ (Group 1). The shaded area denotes the detection limit

paired and unpaired samples. When significant differences were found by this method additional comparisons of values obtained at repeated time points were also performed using Wilcoxon's tests to locate the point at which the curves tended to deviate from each other. Areas were calculated according to the trapezoidal rule. Correlation was measured by Pearson's product-moment correlation coefficient, $r$.

\section{Results}

\section{Plasma Glucose and C-Peptide Concentrations (Group 1)}

In normal subjects blood glucose concentrations rose from a mean basal value of $5.3 \pm 0.2 \mathrm{mmol} / 1$ to a mean peak of $8.7 \pm 0.5 \mathrm{mmol} / 1$ at $60 \mathrm{~min}$ after administration of glucose. In the diabetic patients the mean basal glucose concentration was $13.2 \pm 2.7 \mathrm{mmol} / \mathrm{l}$ and increased to a maximum of $22.0 \pm 1.8 \mathrm{mmol} / \mathrm{l}$ at $90 \mathrm{~min}$ after administration of glucose. As expected C-peptide concentration increased considerably in the normal subjects.

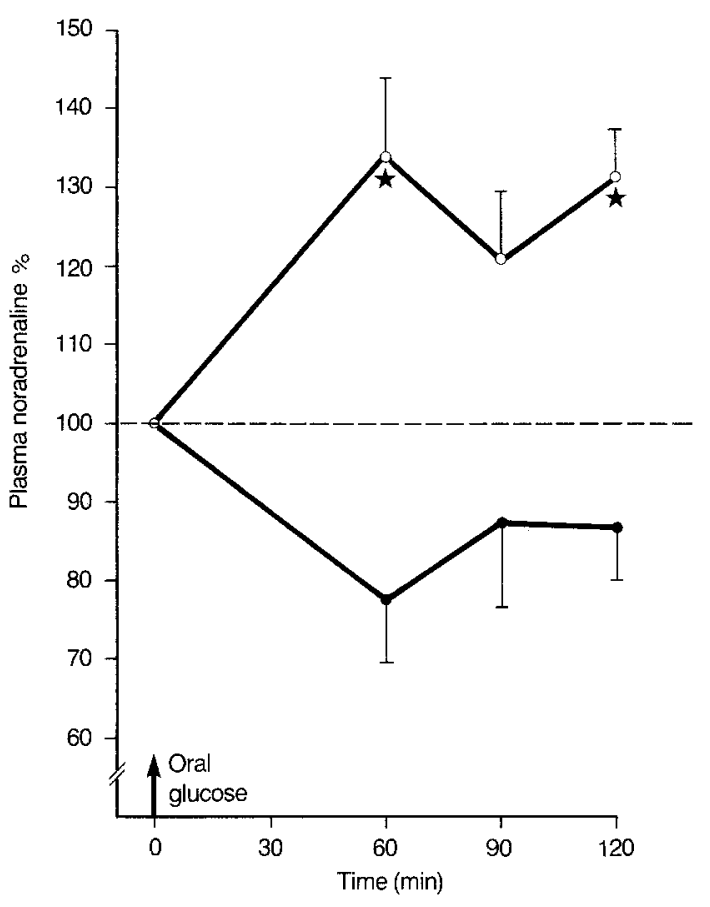

Fig. 2. Plasma noradrenaline concentrations (mean \pm SEM) before and after an oral glucose load in six Type 1 diabetic patients (-) and in seven normal subjects $(\mathrm{O}-\mathrm{O})$ (Group 1). In each subject the values after oral glucose were expressed in percentage of the mean noradrenaline concentration in the period which preceded the oral glucose load. The area of increase in plasma noradrenaline over basal values after oral glucose was significant in normal subjects but not in diabetic patients. $\star$ refer to differences between the two groups of subjects at specific time points $(\star p<0.01)$.

Basal values were very low in the diabetic patients and there was no increase after oral glucose (Fig. 1).

\section{Plasma Catecholamines (Group 1)}

The mean basal plasma NA concentrations were $1.48 \mathrm{nmol} / \mathrm{l}$ (range $0.95-2.13 \mathrm{nmol} / 1$ ) and $0.89 \mathrm{nmol} / 1$ (range $0.36-1.66 \mathrm{nmol} / 1$ ) in normal subjects and diabetic patients, respectively (NS). In the normal subjects, the plasma NA concentration increased significantly during the glucose tolerance test (mean increase 21\% 


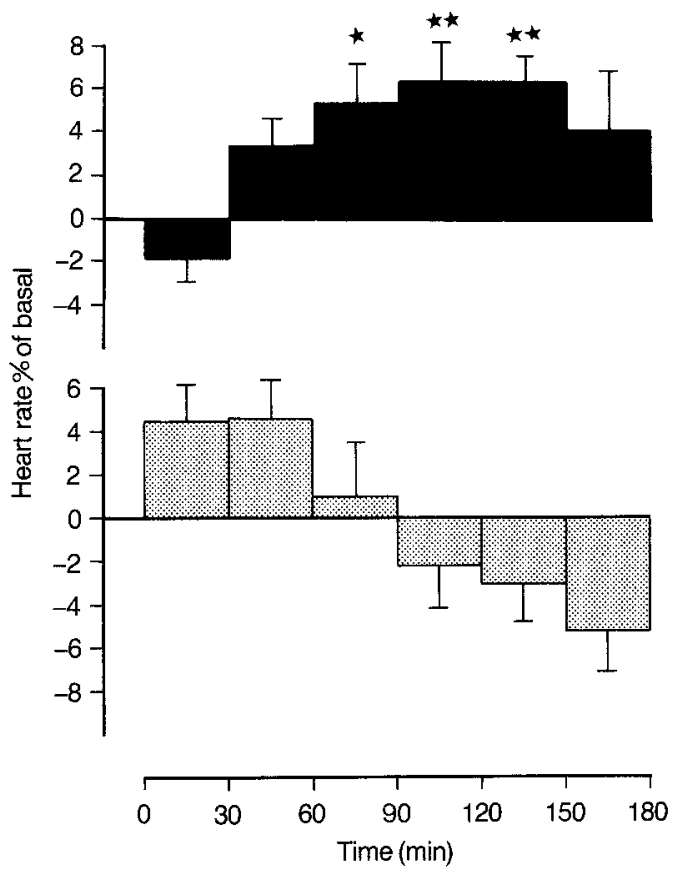

Fig. 3. Increase in heart rate above basal values (mean $\pm S E M$ ) in 30 min periods in eight normal subjects ( $\boldsymbol{U})$ and in eight Type 1 diabetic patients (娄). The area of increase in heart rate above basal values after oral glucose was significant in normal subjects but not in Type 1 diabetic patients. The symbols denote significant increments in heart rate at specific points of time in the normal subjects $(\star p<0.05$, $\star \star p<0.02$ ). There were significant differences between diabetic and control subjects at specific time points (from 90 to $180 \mathrm{~min}$, $p<0.01,0.01$ and 0.05 , respectively)

calculated as the area of increase over basal levels, $p<0.02$, Fig. 2). In the diabetic patients plasma NA did not change after oral glucose (mean change $-13 \%$ ). There was a significant difference in plasma NA after oral glucose in diabetic patients and controls subjects, calculated as area under the curve (Fig. 2, $p<0.01$ ). Plasma adrenaline did not change in either diabetic patients or control subjects. In two normal subjects plasma NA concentration was measured in a similar experiment where only the water load was given; it decreased slightly during this test.

\section{Heart Rate (Group 2)}

The mean heart rates were 64.5 and 72.2 beats $/ \mathrm{min}$ in normal and diabetic subjects respectively (NS). In the normal subjects the heart rate increased from $30 \mathrm{~min}$ after the glucose load was given to a maximum value at 90-150 min (Fig. 3). The mean increase calculated as the area over basal values was $3.5 \%(p<0.05$, Fig. 3$)$. Several, but not all, of the diabetic patients tended to increase the heart rate immediately after glucose was given, but thereafter the heart rate decreased in these patients. However, the mean heart rate did not increase significantly in the Type 1 diabetic subjects during the glucose tolerance test (mean increase $0.5 \%$ ). The mean area of increase in heart rate after oral glucose was not signifi-
Table 2. Analysis of changes in heart rate and systolic blood pressure during an oral glucose load in two normal subjects and two diabetic patients (group 3)

\begin{tabular}{|c|c|c|c|c|}
\hline & \multicolumn{2}{|c|}{$\begin{array}{l}\text { Area of increase } \\
\text { ( } \% \text { of basal) }\end{array}$} & \multicolumn{2}{|c|}{$\begin{array}{l}\text { Correlation of heart } \\
\text { rate with systolic } \\
\text { blood pressure }\end{array}$} \\
\hline & $\begin{array}{l}\text { Heart } \\
\text { rate }\end{array}$ & $\begin{array}{l}\text { Systolic } \\
\text { blood } \\
\text { pressure }\end{array}$ & $r$ & $p$ \\
\hline \multicolumn{5}{|c|}{$\begin{array}{l}\text { Normal } \\
\text { subjects }\end{array}$} \\
\hline $\begin{array}{l}1 \\
2\end{array}$ & $\begin{array}{r}6 \\
10\end{array}$ & $\begin{array}{l}3 \\
3\end{array}$ & $\begin{array}{l}0.57 \\
0.81\end{array}$ & $\begin{array}{l}<0.001 \\
<0.001\end{array}$ \\
\hline \multicolumn{5}{|c|}{$\begin{array}{l}\text { Diabetic } \\
\text { patients }\end{array}$} \\
\hline 1 & 0 & -13 & NS & \\
\hline 2 & -2 & -2 & NS & \\
\hline
\end{tabular}

cantly different in diabetic and control subjects, although there were significant differences at several time points (from 90 to $180 \mathrm{~min}, p<0.01,0.01$ and 0.05 , respectively). In three normal subjects the heart rate was followed for $3 \mathrm{~h}$ after administration of the water load. The heart rate tended to decrease initially during the experiment but had returned to near basal levels at $3 \mathrm{~h}$.

\section{Heart Rate and Arterial Blood Pressure (Group 3)}

In two normal subjects the heart rate and systolic arterial blood pressure increased in parallel after oral glucose whereas systolic blood pressure remained unchanged or decreased slightly in two diabetic subjects. One of the diabetic patients showed an early rise in heart rate after oral glucose while in the other patient the heart rate did not change during the experiment. There was a highly significant correlation between the heart rate and systolic arterial blood pressure in the two normal subjects but not in the two diabetic patients (Table 2). Diastolic blood pressure remained unchanged in all subjects.

\section{Discussion}

Most studies of cardiovascular function in diabetes have focussed on long-term diabetic complications or poorly controlled diabetes and the studies have generally been done with patients in the fasting state. Few studies have attempted to clarify whether glucose or insulin administration have acute effects on cardiovascular function [2]. In the present study, we show that an oral glucose load increased plasma NA and heart rate in normal subjects but not in Type 1 diabetic patients. The increase in these two parameters in the normal subjects after oral glucose is unlikely to be due to non-specific factors because in control experiments (where no 
glucose was given) neither heart rate nor plasma NA increased. Several authors have shown that both intravenous insulin administration [1-3] and an oral glucose load increase plasma NA [8-10]. The rise in plasma NA concentration after insulin administration is not a counter-regulatory response to decrements in blood glucose concentration because a similar increase in plasma NA may be observed if blood glucose is kept constant after insulin administration by a glucose infusion $[2,3]$.

The rise in plasma NA after insulin and glucose administration may be due to an increase in sympathetic nervous activity, a decrease in the plasma clearance of NA or a release of NA from the adrenal medulla. Plasma clearance of NA has been reported to increase or to remain unchanged after increments in endogenous insulin release or administration of exogenous insulin, respectively $[3,11]$. Unfortunately, in these studies the calculated clearance values were based on measurements of steady-state NA concentration in venous rather than in arterial blood. The absolute clearance values reported in these studies are therefore not correct $[12,13]$, but these results make it unlikely that the rise in plasma NA after oral glucose or insulin injection is due to reduction in the plasma clearance of NA. The rise in plasma NA observed after oral glucose is unlikely to be derived from the adrenal medulla because plasma adrenaline did not change. Furthermore, it has been shown that plasma NA increased during insulin-induced hypoglycaemia in adrenalectomized patients in whom the adrenaline response was completely abolished [14]. These results suggest that the rise in plasma NA after insulin and oral glucose administration reflects an increase in sympathetic nervous activity.

In normal subjects the rise in plasma NA after oral glucose may be due to the rise in endogenous insulin secretion. This is so since intravenous infusion of insulin in doses that resulted in high physiological increments in plasma insulin concentration increased plasma NA [3] and, as shown in the present study, the rise in plasma NA after oral glucose was absent in insulin-dependent diabetics. However, further studies are needed to define the role of endogenous insulin secretion for the increase in plasma NA after oral glucose in normal subjects. The rise in plasma NA after insulin and oral glucose administration may be of physiological importance because arterial blood pressure decreased in sympathectomized patients after insulin [15-18] and probably also in sympathectomized non-diabetic subjects after oral glucose [19]. This abnormality may be due to the lack of increase in NA release when plasma insulin increases $[2,18]$.

During an oral glucose load normal subjects demonstrated a small but significant increase in heart rate, whereas the diabetic patients showed no change. It is tempting to speculate that the lack of rise in heart rate during the oral glucose test in diabetic subjects was due to a lack of increase in sympathetic nervous activity. However, this suggestion is probably not correct because neither we [5] nor Zwillich et al. [20] were able to inhibit the rise in heart rate after insulin and glucose, respectively, by $\beta$-adrenoceptor blockade.

It is unlikely that the lack of increase in heart rate and plasma NA in diabetic patients in the present study was due to autonomic neuropathy, since no patient had signs of peripheral neuropathy and all had a short duration of diabetes. We have previously shown that intravenous insulin administration increased heart rate and plasma NA even in long-term diabetic patients without complications, whereas only the rise in heart rate after insulin was present in patients with complications [2].

We cannot exclude the possibility that the increase in heart rate in normal subjects was due to an increase in baroreceptor activity secondary to an increase in blood flow. However, this is unlikely since arterial blood pressure increased rather than decreased after oral glucose. Furthermore, it has previously been shown that oral glucose increased splanchnic blood flow to the same extent in Type 2 diabetic subjects and control subjects [21].

In conclusion, our study showed that regulation of sympathetic nervous activity and cardiovascular function is abnormal in Type 1 diabetic patients during an oral glucose test. Although the mechanisms of these abnormalities are unknown at present, our results are compatible with the view that insulin may serve as an important signal to or regulator of the cardiovascular system after oral glucose.

Acknowledgements. This study was supported by the Danish Medical Research Council (12-1365, 512-20320), the Danish Hospital Foundation for Medical Research, Region of Copenhagen, The Faroe Islands and Greenland (5/81), and P.Carl Petersen's Foundation. Presented in part at the 18th Annual Meeting of the European Association for the Study of Diabetes, Budapest, 1-4 September 1982.

\section{References}

1. Christensen NJ (1974) Plasma norepinephrine and epinephrine in untreated diabetics, during fasting and after insulin administration. Diabetes 23:1-8

2. Christensen NJ, Gundersen HJG, Hegedüs L, Jacobsen F, Mogensen CE, Østerby R, Vittinghus $E$ (1980) Acute effects of insulin on plasma noradrenaline and the cardiovascular system. Metabolism 29 (suppl 1): 1138-1145

3. Rowe JW, Young JB, Minaker KL, Stevens AL, Pallotta J, Landsberg L (1981) Effect of insulin and glucose infusions on sympathetic nervous system activity in normal man. Diabetes 30: 219-225

4. Page MMcB, Smith RBW, Watkins PJ (1976) Cardiovascular effects of insulin. Br Med J 1: 430-432

5. Jacobsen F, Christensen NJ (1979) Stimulation of heart rate by insulin: uninfluenced by beta-adrenergic receptor blockade in rabbits. Scand J Clin Lab Invest 39: 253-256

6. Heding LG (1975) Radioimmunological determination of human C-peptide in serum. Diabetologia 11: 541-548

7. Christensen NJ, Vestergaard P, Sørensen T, Rafaelsen OJ (1980) Cerebrospinal fluid adrenaline and noradrenaline in depressed patients. Acta Psychiatr Scand 61: 178-182

8. Young JB, Rowe JW, Pallotta JA, Sparrow D, Landsberg L (1980) Enhanced plasma norepinephrine response to upright posture and oral glucose administration in elderly human subjects. Metabolism 29: 532-539 
9. Welle S, Lilavivat U, Campbell RG (1981) Thermic effect of feeding in man: increased plasma norepinephrine levels following glucose but not protein and fat consumption. Metabolism 30 : 953-958

10. Kleinbaum J, Shamoon H (1982) Selective counterregulatory hormone responses after oral glucose in man. J Clin Endocrinol Metab 55: 787-790

11. Esler M (1982) Assessment of sympathetic nervous function in humans from noradrenaline plasma kinetics. Clin Sci 62: 247-254

12. Christensen NJ (1982) Editorial: Sympathetic nervous activity and age. Eur J Clin Invest 12: 91-92

13. Hilsted J, Christensen NJ, Madsbad S (1983) Whole body clearance of norepinephrine: The significance of arterial sampling and of surgical stress. J Clin Invest 71: 500-505

14. Järhult J, Farnebo L-O, Hamberger B, Holst J, Schwartz TW (1981) The relation between catecholamines, glucagon and pancreatic polypeptide during hypoglycaemia in man. Acta Endocrinol 98: 402-406

15. French EB, Kilpatrick R (1955) The role of adrenaline in hypoglycaemic reactions in man. Clin Sci 14: 639-651

16. Miles DW, Hayter CJ (1968) The effect of intravenous insulin on the circulatory responses to tilting in normal and diabetic subjects with special reference to baroceptor reflex block and atypical hypoglycaemic reactions. Clin Sci 34: 419-430
17. Page MMcB, Watkins PJ (1976) Provocation of postural hypotension by insulin in diabetic autonomic neuropathy. Diabetes 25 : $90-95$

18. Mathias CJ, Frankel HL, Turner RC, Christensen NJ (1979-80) Physiological responses to insulin hypoglycaemia in spinal man. Paraplegia 17: 319-326

19. Seyer-Hansen K (1977) Postprandial hypotension. Br Med J 2: 1262

20. Zwillich C, Martin B, Hofeldt F, Charles A, Subryan V, Burman K (1981) Lack of effects of beta sympathetic blockade on the metabolic and respiratory responses to carbohydrate feeding. Metabolism 30: 451-456

21. Felig P, Wahren J, Hendler R (1978) Influence of maturity-onset diabetes on splanchnic glucose balance after oral glucose ingestion. Diabetes 27: 121-126

Received: 21 December 1982

and in revised form: 25 April 1983

Dr. L. Hegedüs

Department of Internal Medicine and Endocrinology

Herlev Hospital

DK-2730 Herlev

Denmark 